\title{
ВХОЖДЕНИЕ МОЛЕКУЛЯРНОЙ ВОДЫ В СТРУКТУРУ МИНЕРАЛОВ ГРУППЫ ВЕЗУВИАНА
}

\section{Паникоровский Т.Л., Яковенчук В.Н., Базай А.В.} ФИЦ КНЦ РАН

В скарноидах Ковдорского флогопитового комплекса отмечено широкое разнообразие минералов группы везувиана (МГВ) [1-3]. Наиболее интересными с точки зрения кристаллохимии являются выделения позднего гидратированного $R E E$-содержащего МГВ, который в виде оранжевых корок с 15-20 мас. \% $R E E_{2} \mathrm{O}_{3}$ нарастает на более ранние темного-коричневые призматические агрегаты негидратированного везувиана (рис. 1). Химический состав таких корок приведён в таблице 1.

Таблица 1. Химический состав РЗЕ-содержащего МГВ из Ковдорского массива.

\begin{tabular}{|c|c|c|c|c|c|c|c|}
\hline Образец & 1 & 2 & 3 & 4 & 5 & 6 & 7 \\
\hline $\mathrm{SiO}_{2}$ & 26.96 & 30.62 & 34.12 & 28.95 & 32.10 & 34.23 & 33.31 \\
\hline $\mathrm{TiO}_{2}$ & 5.60 & 0.75 & 1.06 & 1.86 & 0.93 & 0.49 & 0.30 \\
\hline $\mathrm{Al}_{2} \mathrm{O}_{3}$ & 4.19 & 5.82 & 9.64 & 7.25 & 9.02 & 10.46 & 9.32 \\
\hline $\mathrm{Fe}_{2} \mathrm{O}_{3}$ & $5.30 * *$ & 0.00 & 0.00 & 0.00 & 0.00 & 0.00 & 0.00 \\
\hline $\mathrm{FeO}$ & $0.78^{* *}$ & 8.58 & 7.20 & 7.01 & 6.95 & 6.82 & 6.59 \\
\hline $\mathrm{MnO}$ & 0.05 & 0.03 & 0.04 & 0.02 & 0.05 & 0.08 & 0.08 \\
\hline $\mathrm{MgO}$ & 4.42 & 4.69 & 4.14 & 4.30 & 4.11 & 4.25 & 4.47 \\
\hline $\mathrm{CaO}$ & 18.39 & 23.54 & 30.21 & 24.59 & 29.05 & 31.42 & 29.07 \\
\hline $\mathrm{Na}_{2} \mathrm{O}$ & 0.29 & 0.64 & 0.40 & 0.50 & 0.16 & 0.30 & 0.41 \\
\hline $\mathrm{SO}_{3}$ & 0.13 & 0.11 & 0.05 & 0.08 & 0.12 & 0.12 & 0.19 \\
\hline $\mathrm{SrO}$ & 0.40 & 0.47 & 0.52 & 0.41 & 0.44 & 0.54 & 0.37 \\
\hline $\mathrm{La}_{2} \mathrm{O}_{3}$ & 2.97 & 3.65 & 1.62 & 3.82 & 2.41 & 1.97 & 2.35 \\
\hline $\mathrm{Ce}_{2} \mathrm{O}_{3}$ & 10.04 & 7.06 & 2.47 & 5.28 & 3.15 & 2.72 & 3.51 \\
\hline $\mathrm{Pr}_{2} \mathrm{O}_{3}$ & 1.52 & 0.91 & 0.32 & 0.76 & 0.23 & 0.28 & 0.32 \\
\hline $\mathrm{Nd}_{2} \mathrm{O}_{3}$ & 3.23 & 1.28 & 0.45 & 1.27 & 0.63 & 0.30 & 0.40 \\
\hline $\mathrm{Sm}_{2} \mathrm{O}_{3}$ & 0.35 & 0.20 & 0.00 & 0.00 & 0.00 & 0.00 & 0.00 \\
\hline $\mathrm{Gd}_{2} \mathrm{O}_{3}$ & 0.24 & 0.12 & 0.06 & 0.13 & 0.00 & 0.00 & 0.00 \\
\hline $\mathrm{PbO}$ & 0.72 & 0.00 & 0.00 & 0.00 & 0.00 & 0.00 & 0.00 \\
\hline $\mathrm{ThO}_{2}$ & 2.86 & 1.95 & 0.52 & 1.58 & 0.79 & 0.27 & 0.41 \\
\hline $\mathrm{H}_{2} \mathrm{O}^{*}$ & $6.11^{* *}$ & 3.91 & 4.34 & 4.63 & 4.50 & 4.74 & 4.22 \\
\hline $\mathrm{F}$ & 0.31 & 0.27 & 0.28 & 0.24 & 0.29 & 0.27 & 0.28 \\
\hline $\mathrm{Cl}$ & 0.08 & 0.12 & 0.15 & 0.12 & 0.12 & 0.10 & 0.11 \\
\hline $\mathrm{O} \equiv \mathrm{F}$ & 0.13 & 0.11 & 0.12 & 0.10 & 0.12 & 0.11 & 0.12 \\
\hline $\mathrm{O} \equiv \mathrm{Cl}$ & 0.02 & 0.03 & 0.04 & 0.03 & 0.03 & 0.02 & 0.03 \\
\hline Сумма & 94.79 & 95.61 & 98.30 & 93.51 & 97.56 & 100.47 & 96.83 \\
\hline
\end{tabular}

*Соотношение $\mathrm{Fe}^{2+} / \mathrm{Fe}^{3+}$ определено, исходя из данных Мёссбауэровской спектроскопии

**Содержание $\mathrm{H}_{2} \mathrm{O}$ измерено методом термогравиметрии.

Исследование данного материала методом термогравиметрии (рис. 2) показало аномальную для МГВ 2-этапную потерю массы в $6.11 \%$. Первый этап потери массы (-1.87 мас. \%) в интервале температур 300-600 ${ }^{\circ} \mathrm{C}$, вероятно, соответствует потере $\left(\mathrm{H}_{4} \mathrm{O}_{4}\right)^{4-}$ групп [8]. Второй этап потери массы сопровождается эндотермическим пиком при температуре $1018{ }^{\circ} \mathrm{C}(-4.24$ мас. \%) и отвечает потере $\mathrm{OH}^{-}$-групп, связанных с позициями кислорода О10 и О11 [9], и неструктурированной воды, связанной с вакансиями в позициях $X 3$. Общая потеря массы соответствует $24.83 \mathrm{OH}^{-}$в расчете на формулу, тогда как в «обычном» везувиане содержится лишь 9 ОН-групп [5].

Изучение этого образца методом инфракрасной спектроскопии подтвердило высокую степень его гидратированности (рис. 3). В спектре минерала, помимо валентных колебаний О-Н свя- 

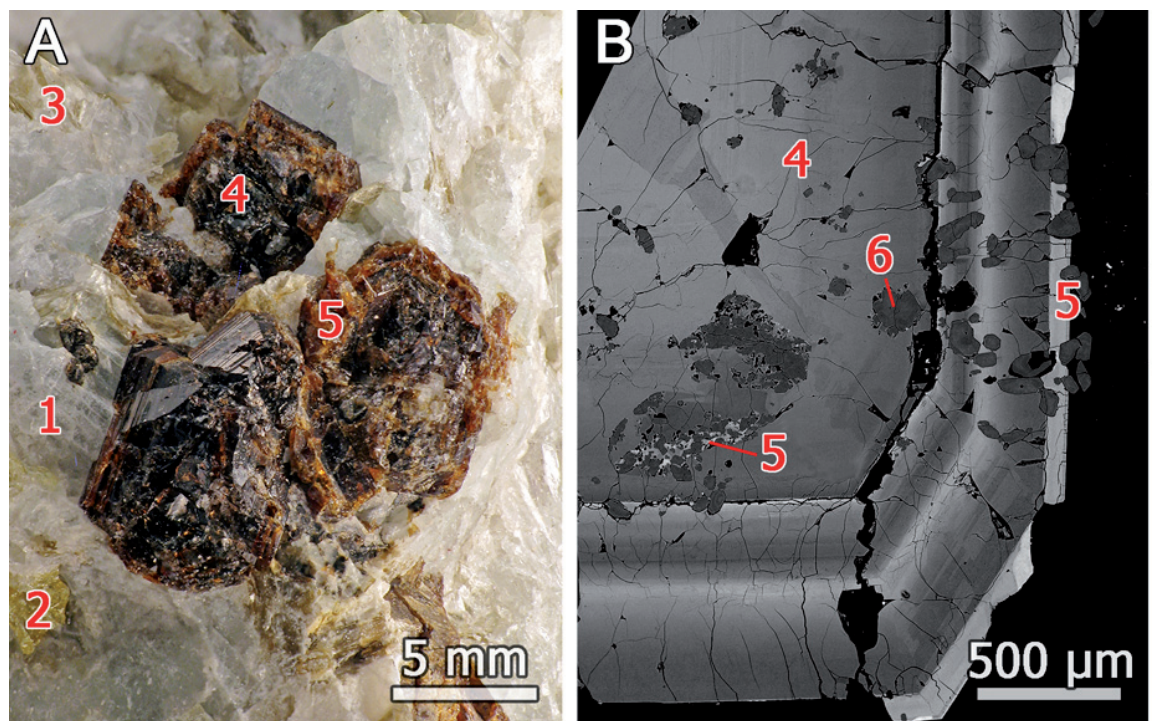

Рис. 1. Фотография (А) и ВSE-изображение (Б) зонального РЗЕ-содержащего (4) и РЗЕ-доминантного в позиции X3 МГВ (5) в кальцитовой матрице (1) с включениями андрадита (2), глаголевита (3) и гидроксилапатита (6).

зей (пики при 3620, 3430 и $3200 \mathrm{~cm}^{-1}$ ), наблюдается пик при $1630 \mathrm{~cm}^{-1}$, характерный для деформационных колебаний Н-O-Н связей в молекулах воды. Следует также отметить сложность спектра в области как валентных, так и деформационных колебаний $\mathrm{Si}-\mathrm{O}$ связей, вероятно, обусловленную тем, что часть кремния в тетраэдрах замещена алюминием.

Структура $R E E$-содержащего МГВ была уточнена в пространственной группе $P 4 / n n c$ до фактора сходимости $R_{1}=0.035$ для 1527 независимых рефлексов с интенсивностью $\left|F_{\mathrm{o}}\right| \geq 4 \sigma_{F}$. В процессе проверки массива данных был обнаружен лишь 1 рефлекс с низкой интенсивностью, нарушающий правила погасания для данной пространственной группы $P 4 / n n c$. При уточнении структуры с фиксировано-полными заселенностями позиций $Z$-группы катионов фактор сходимости увеличился до $R_{1}=0.05$, но значительно возросли факторы тепловых колебаний $Z 1$ и $Z 2$ позиций. Значение фактора рассеяния для $Z 1$ позиции составило $8.40 e^{-}$, что, вкупе с существенно увеличенной длиной $<Z 1-\mathrm{O}>$ связи $1.718 \AA$, соответствует $40 \%$ вакантности этой позиции. Существующие вакансии, согласно данным химического анализа, заняты $\mathrm{H}_{4} \mathrm{O}_{4}$-кластерами по схеме $\mathrm{SiO}_{4}^{4-\leftrightarrow}\left[\mathrm{H}_{4} \mathrm{O}_{4}\right]^{4-.}$ Следует отметить, что изоморфизм такого типа распространён в МГВ с низкотемпературным генезисом

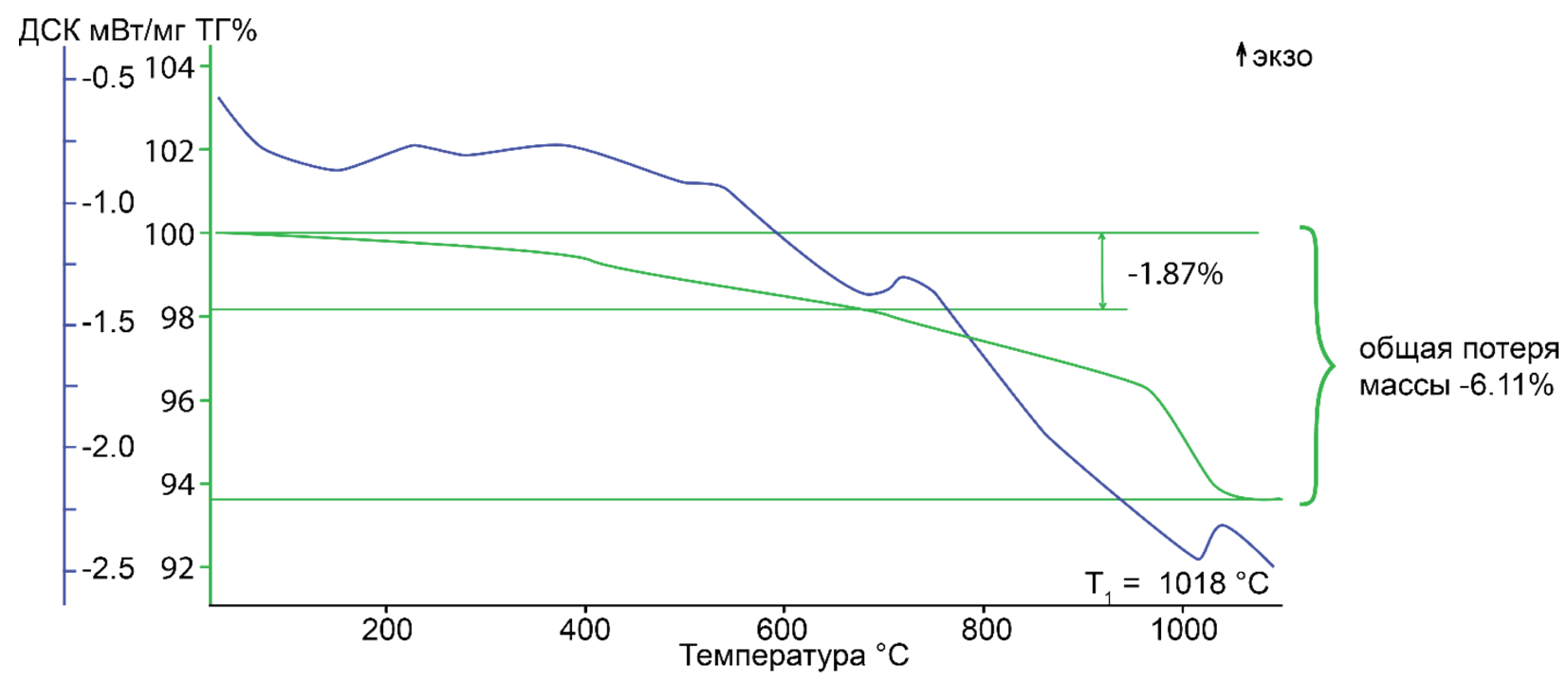

Рис. 2. Кривые термогравиметрии (зеленая линия, мас.\%) и дифференциальной сканирующей калориметрии (синяя линия) для корки редкоземельного МГВ. 


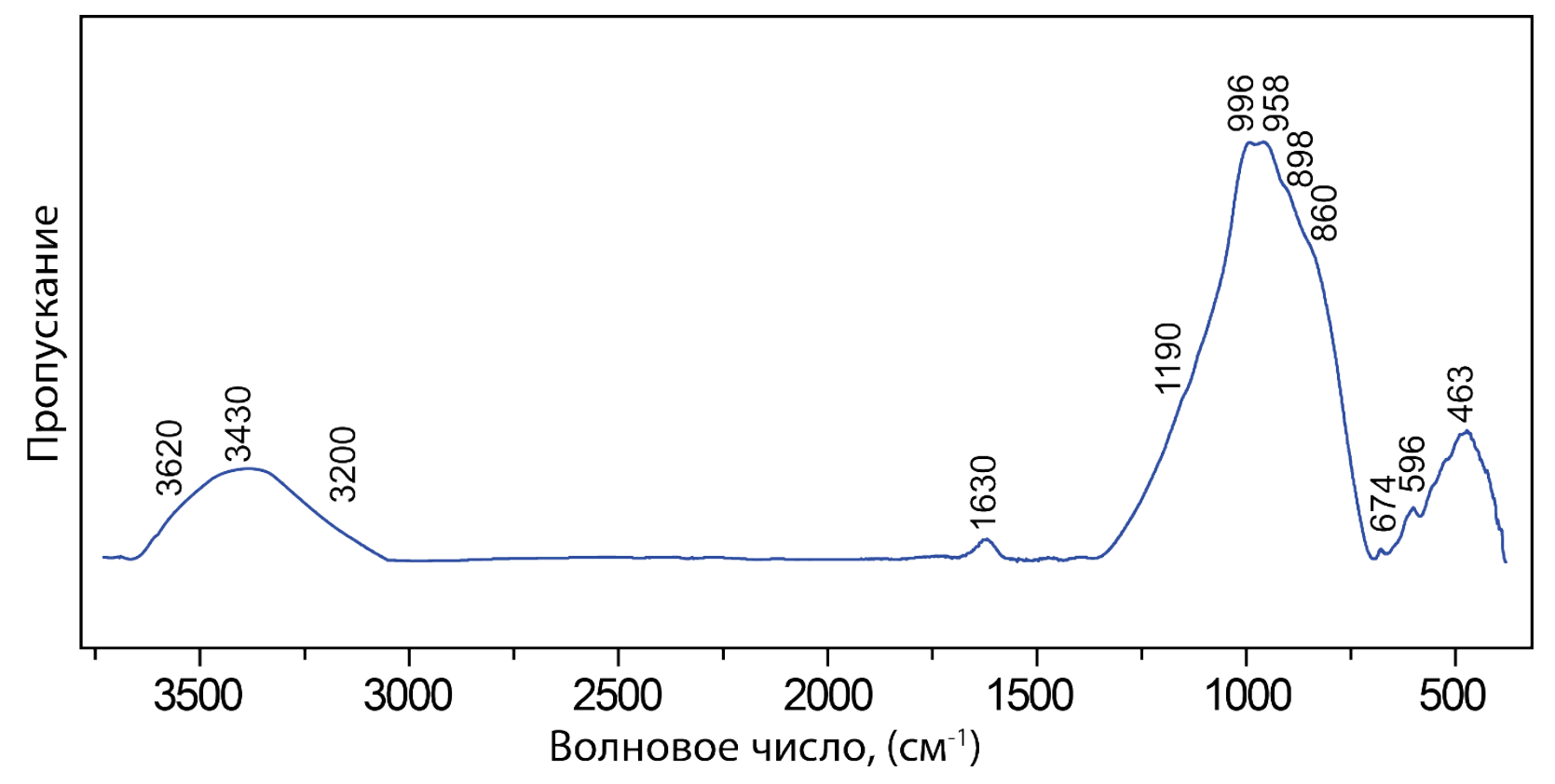

Рис. 3. Инфракрасный спектр REE-содержащего МГВ.

(200-300 $\left.{ }^{\circ} \mathrm{C}\right)$. Для позиций $Z 2$ и $Z 3$, где также наблюдается недостаток кремния, рассеивающие факторы этих позиций составили 10.50 и $12.04 e^{-}$, соответственно. Средние величины $<Z 2-\mathrm{O}>u<Z 3-\mathrm{O}>$ связей составили 1.691 и $1.644 \AA$, что хорошо согласуется с уточнёнными заселенностями этих позиций $\mathrm{Si}_{0.75}$ и $\mathrm{Si}_{0.86}$, соответственно. Поскольку изоморфизм гидрогранатового типа $\mathrm{SiO} 44-\leftrightarrow[\mathrm{H} 4 \mathrm{O} 4] 4-$ невозможен в силикатных диортогруппах, дефицит кремния в Z3 позиции наиболее удовлетворительно объясняется внедрением Al3+ в эту позицию.

Позиции $X 1$ и $X 2$ с координацией 7-8 заняты исключительно атомами Са, в то время как в наиболее крупную (по полиэдрическому объёму) позицию $X 3$ могут входить такие трёхвалентные катионы, как $R E E^{3+}$ и $\mathrm{Bi}^{3+}$. Уточнённая заселённость $X 3$ позиции $\mathrm{Ce}_{0.44} \mathrm{Ca}_{0.36} \square_{0.20}$ (рис. 4) находится в хорошем согласии с уточнённым фактором рассеяния $32.72 e^{-,}$соответствующей длиной $<X 3-\mathrm{O}>$ связи, равной $2.584 \AA$, и данными твердотельного ЯМР на ядрах ${ }^{139} \mathrm{La}$. Редкоземельные элементы также могут частично входить в $X 4$ позицию, уточнённая заселённость которой составила $\mathrm{Ca}_{0.74} \mathrm{Ce}_{0.26}$. Образование вакансий в позиции $X 3$ связано с внедрением катионов $\mathrm{Th}^{4+}$ и $R E E^{3+}$ в структуру минерала путём замещений $2 \mathrm{Ca}^{2+} \leftrightarrow \mathrm{Th}^{4+}+\square ; 3 \mathrm{Ca}^{2+} \leftrightarrow 2 R E E^{3+}+\square$.
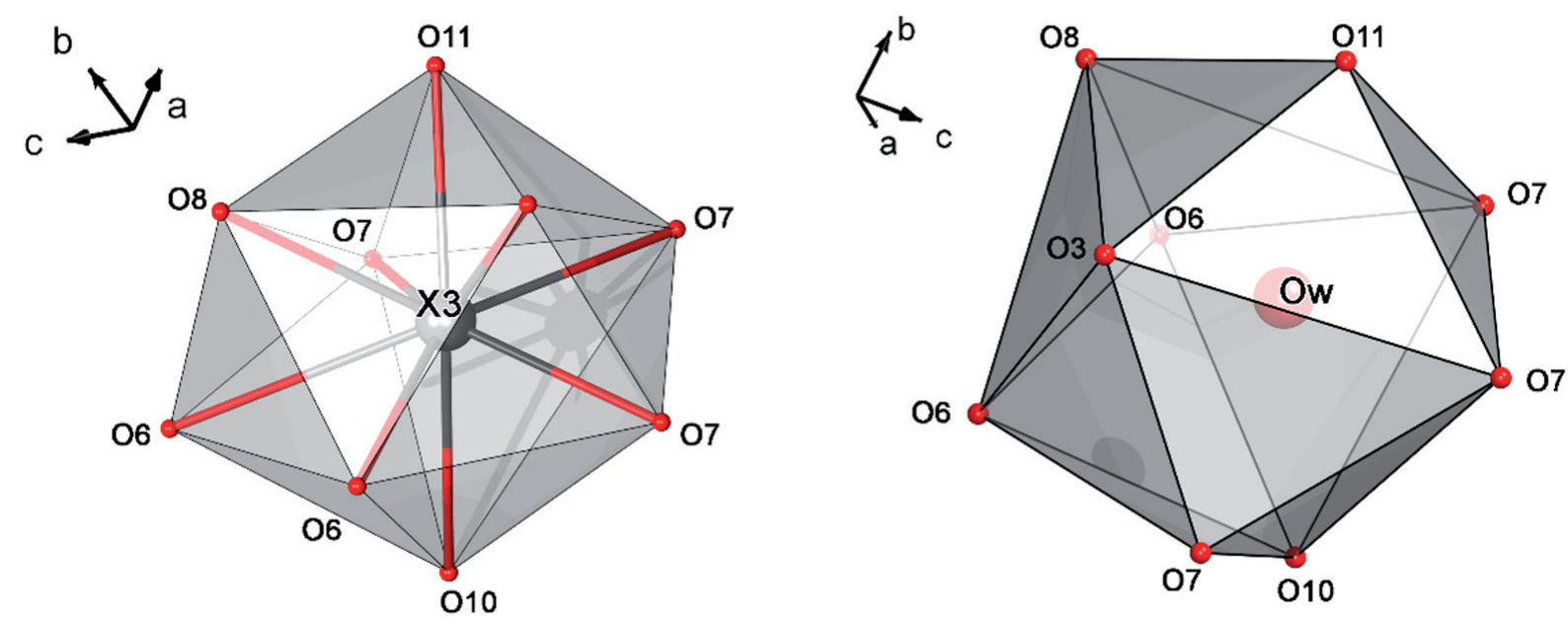

Рис. 4. Локальная координация $X 3$ позиции и окружение позиции Ow. 
Магний доминирует в $Y 1$ и $Y 3$ позициях структуры рассматриваемого минерала. Для тетрагонально-пирамидальной позиции $Y 1$ фактор рассеяния составил $6.0 e^{-}$, что соответствует половинной заселённости этой позиции, $\mathrm{Mg}_{0.50}$. Октаэдры $Y 2$ и $Y 3$ имеют значительно увеличенные по сравнению с остальными МГВ средние длины связи $<Y 2-\mathrm{O}>$ и $<Y 3-\mathrm{O}>$, составившие 1.976 и $2.019 \AA$, соответственно. Уточнённые факторы рассеяния составили 14.66 и $15.78 e^{-}$, что соответствует заселенностям $\left[(\mathrm{Al}, \mathrm{Mg})_{0.82}(\mathrm{Fe}, \mathrm{Ti})_{0.18}\right]_{1.00}$ и $\left[(\mathrm{Mg}, \mathrm{Al})_{0.73}(\mathrm{Fe}, \mathrm{Ti})_{0.27}\right]_{1.00}$ для $Y 2$ и $Y 3$ позиций, соответственно.

Рядом с позицией $X 3$ (расстояние $X 3$-Ow составило $0.35 \AA$ ) была локализована позиция молекулярной воды $\mathrm{Ow}$ (рис. 4), уточнённая заселённость которой составила $\mathrm{Ow}_{0.20}$. Таким образом позиция Ow оказывается заселённой только в том случае, когда позиция $X 3$ вакантна. Присутствие молекулярной воды в структуре редкоземельного МГВ подтверждается данными химического состава (ТГ/ДСК, CHN-анализ) и наличием соответствующего пика в ИК-спектре.

С учетом данных твердотельного ЯМР, а также инфракрасной спектроскопии, общая кристаллохимическая формула рассматриваемого МГВ может быть записана следующим образом, отчётливо указывающего на его соответствие новому минеральному виду:

${ }^{X 1}(\mathrm{Ca})_{\Sigma 2.00}{ }^{X 2}(\mathrm{Ca})_{\Sigma 8.00}{ }^{X 3}\left(\mathrm{Ce}_{3.52} \mathrm{Ca}_{2.88}\left\{\mathrm{H}_{2} \mathrm{O}\right\}_{1.60}\right)_{\Sigma 8.00}{ }^{X 4}\left(\mathrm{Ca}_{0.74} \mathrm{Ce}_{0.26}\right)_{\Sigma 1.00}{ }^{Y 1} \mathrm{Mg}_{\Sigma 1.00}{ }^{Y 2}\left((\mathrm{Al}, \mathrm{Mg})_{3.24}(\mathrm{Fe}, \mathrm{Ti})_{0.76}\right)$ ${ }_{\Sigma 4.00}{ }^{Y 3}\left((\mathrm{Mg}, \mathrm{Al})_{5.84}(\mathrm{Fe}, \mathrm{Ti})_{2.16}\right)_{\Sigma 8.00}^{21}\left(\mathrm{Si}_{1.20}\left(\mathrm{H}_{4} \mathrm{O}_{4}\right)_{0.80}\right)_{\Sigma 2.00}{ }_{Z 2}\left(\mathrm{Si}_{6.00}\left(\mathrm{H}_{4} \mathrm{O}_{4}\right)_{2.00}\right)_{\Sigma 8.00}^{Z 3}(\mathrm{Si})_{\Sigma 8.00}{ }^{\mathrm{T} 1}\left(\mathrm{Al}_{0.32} \square_{3.68}\right)$ ${ }_{\Sigma 4.00}{ }^{\mathrm{T} 2}\left(\mathrm{~S}_{0.07} \square_{0.93}\right)_{\Sigma 1.00} \mathrm{O}_{68.00}(\mathrm{OH}, \mathrm{O})_{\Sigma 9.60}$.

Работа выполнена в рамках гранта РНФ 16-17-10173 на оборудовании РЦ рентгенодифракционных методов исследования СПбГУ.

\section{Литература}

1. Иванюк Г.Ю., Яковенчук В.Н., Пахомовский Я.А. Ковдор. Апатиты: Минералы Лапландии. 2002.325 с.

2. Каверин С.В., Краснова Н.В., Тарасенко Ю.Н. К минералогии апомелилитовых пород Ковдорского массива // Минералогия и Геохимия. Вопросы генезиса эндогенных месторождений. Вып. 7. Л.: Изд. ЛГУ. 1988.

3. Паникоровский Т.Л., Яковенчук В.Н., Иванюк Г.Ю., Кривовичев С.В. Структурная эволюция везувиана из скарноидов Ковдорского массива (Кольский полуостров) // Тр. Ферсмановской научной сессии. ГИ КНЦ РАН. 2017. С. 148-150.

4. Серёдкин М.В. Петрология железорудного и флогопитового месторождений Ковдорского массива. Автореф. диссертации. Москва. 2001. 32 с.

5. Allen F.M., Burnham C.W. A comprehensive structure-model for vesuvianite: symmetry variations and crystal growth // Can. Mineral. 1992. V. 30. P. 1-18.

6. $\quad$ CrysAlisPro, Agilent Technologies, Version 1.171.36.20 release 27-06-2012.

7. Gnos E., Armbruster T. Relationship among metamorphic grade, vesuvianite «rod polytypism», and vesuvianite composition // Amer. Mineral. 2006. V. 91. P. 862-870.

8. Rivas-Mercury, J.M., Pena, P., de Aza, A.H, Turrillas X. Dehydration of $\mathrm{Ca}_{3} \mathrm{Al}_{2}\left(\mathrm{SiO}_{4}\right)_{\mathrm{y}}(\mathrm{OH})_{4(3-\mathrm{y})}(0<\mathrm{y}<$ 0.176) studied by neutron thermodiffractometry // J. Eur. Ceram. Soc. 2008. V. 28. P. 1737-1748.

9. Zabinski W., Wactawska Z., Paluszkiewicz C. Thermal decomposition of vesuvianite. J. Therm. Anal. 1996. V. 46. P. 1437-1447. 